\title{
Apoptosis and Skeletal Muscle in Aging
}

\author{
Giuseppe Musumeci*, Rosa Imbesi, Marta Anna Szychlinska, Paola Castrogiovanni \\ Department of Biomedical and Biotechnological Sciences, Human Anatomy and Histology Section, School of \\ Medicine, University of Catania, Catania, Italy \\ Email: ${ }^{*}$ g.musumeci@unict.it
}

Received 12 March 2015; accepted 20 April 2015; published 22 April 2015

Copyright (C) 2015 by authors and Scientific Research Publishing Inc.

This work is licensed under the Creative Commons Attribution International License (CC BY). http://creativecommons.org/licenses/by/4.0/

(C) (7) Open Access

\begin{abstract}
Apoptosis is highly considered as a possible mechanism in the aging process of skeletal muscle. Age-related apoptosis pathways in aging skeletal muscle are several, and apoptotic stimuli considered as initiators could be of various type, such as calcium, TNF- $\alpha$ and oxidative stress. In the last decade, scientific research has focused on some topics in order to establish an appropriate lifestyle improving the homeostasis of muscle tissue in aging. Physical exercise seems to improve cellular antioxidant defense especially when associated with a good quality of nutrition, thanks to some nutrients, such as carotenoids and oleic acid that have antioxidant properties. A combination of physical exercise, caloric restriction and diet seems to be best strategy to attenuate apoptotic pathways that lead to the loss of skeletal muscle in aging, with all consequence on the physical well-being of the elderly.
\end{abstract}

\section{Keywords}

Apoptosis, Aging, Skeletal Muscle, Exercise, Nutrition

\section{Introduction}

Aging is a condition of life characterized by a decline in physical functions which impairs quality life of old people. Age-related decrease in skeletal muscle quantity is known as sarcopenia. However, it should be also considered the quality of muscle tissue that may be crucial as much as the quantity [1]. Aging determines muscle force decline due to a progressive decrease in anabolism with an increase of catabolism. These physiological events are also accompanied by a reduced muscle regeneration capacity. The unbalanced muscle protein turnover and tissue remodeling are associated with impaired muscle cell recruitment and apoptosis [2]. Apoptosis is a regulated mechanism of cell death, characterized by molecular, biochemical and morphological events, considered as a possible mechanism in the aging process of skeletal muscle [3] [4]. Different apoptotic stimuli, such

*Corresponding author.

How to cite this paper: Musumeci, G., Imbesi, R., Szychlinska, M.A. and Castrogiovanni, P. (2015) Apoptosis and Skeletal Muscle in Aging. Open Journal of Apoptosis, 4, 41-46. http://dx.doi.org/10.4236/ojapo.2015.42004 
as oxidative stress, calcium and TNF- $\alpha$, may be considered as initiators of the apoptotic signaling in aged skeletal muscle [2]-[7]. There are two pathways of apoptosis determining the synthesis of extracellular or intracellular signals promoting cell death (Figure 1) [8], the breakdown of the cytoskeleton promoting cell shrinkage and the destruction of the nuclear envelope and the fragmentation of the DNA [9]-[11] (Figure 2). The extrinsic pathway is activated by pro-apoptotic receptors (ligands) on the cell surface (Figure 1) [8] [12]. The intrinsic pathway of apoptosis is instead regulated by mitochondrial parameters (Figure 1) [11]. Mitochondrial mediated apoptosis may initiate through the release of pro-apoptotic proteins into the cytosol also due to age-related mitochondrial dysfunctions [13] [14]. However, the mitochondria also contain anti-apoptotic proteins [11]. Mitochondrial pro- and anti-apoptotic proteins belong to the B-cell lymphoma-2 (Bcl-2) family [11] and the balance between them determines apoptosis [15].

\section{Aged Skeletal Muscle}

Age-related apoptosis in skeletal muscle is a topic widely discussed in the scientific literature. Research data reported that in old age the mitochondrial caspase-independent apoptotic pathway, through the apoptosis inducing factor (AIF) and the endonuclease G (Endo G) may play a more relevant role in skeletal muscle loss than caspase-mediated apoptosis, through cytochrome c, Bax/Bcl2 [4] [16]. There is also, thought little, evidence that levels of cytosolic $\mathrm{Ca}^{2+}$ increase with age [6] and that in this condition, the activation of the endoplasmic reticulum-mediated apoptotic pathway is stimulated [4]. Degradation and resynthesis of skeletal muscle proteins are

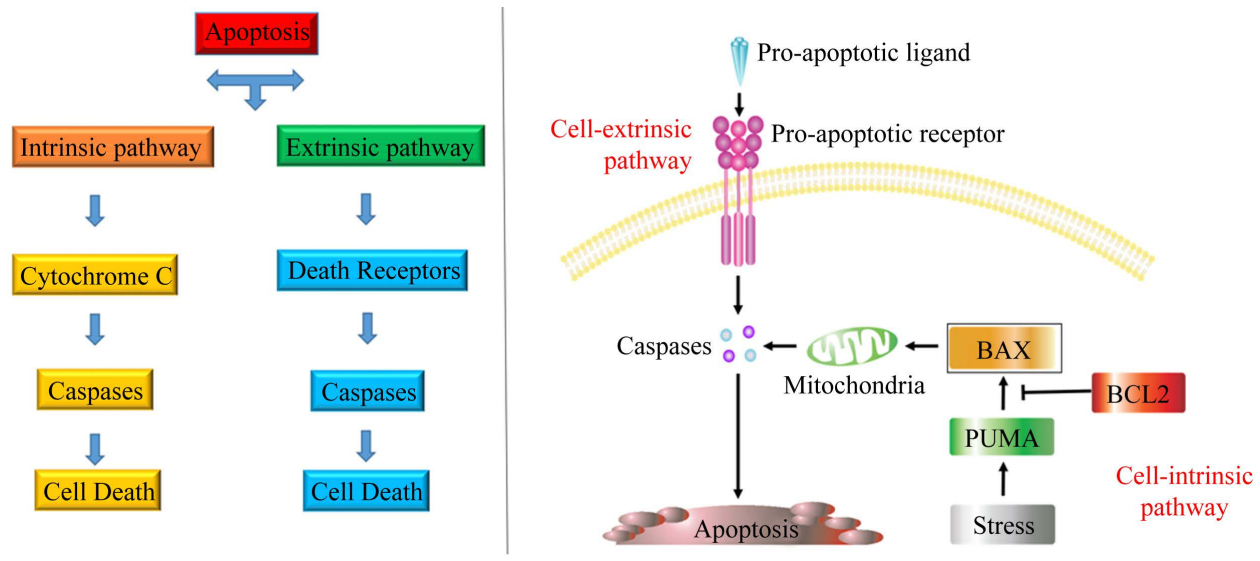

Figure 1. Schematic illustration of the intrinsic and extrinsic pathways of apoptosis.

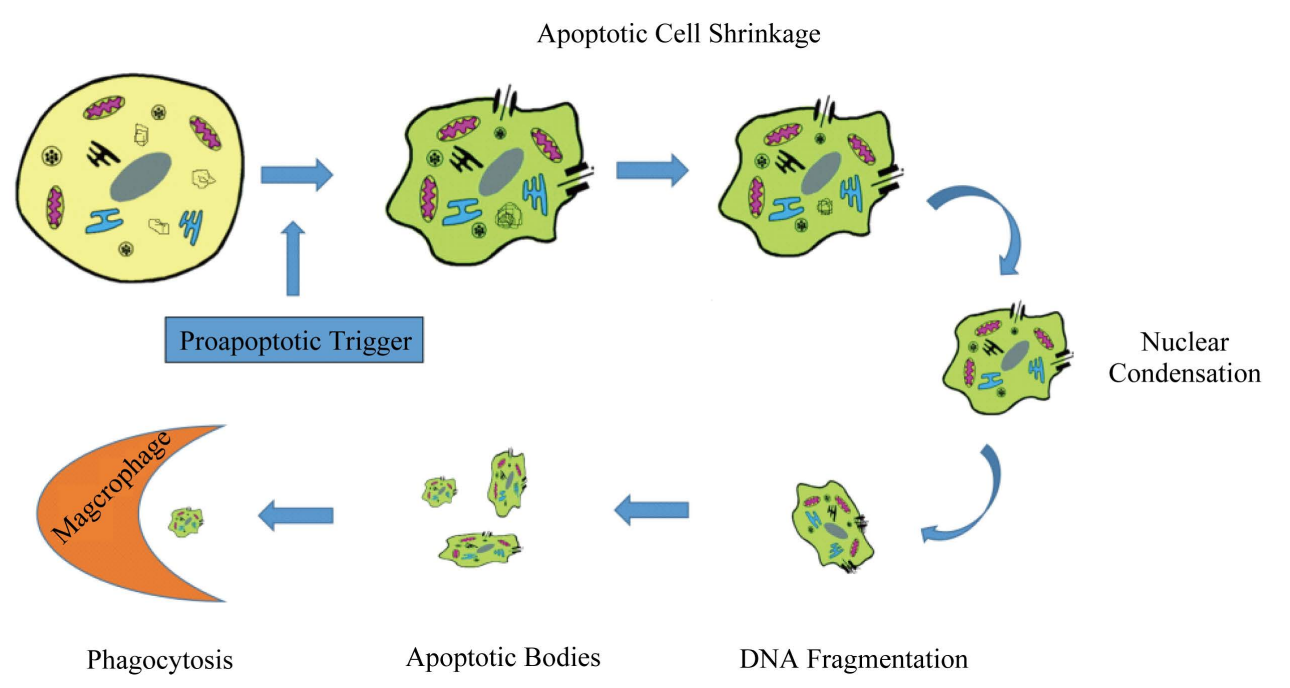

Figure 2. Schematic illustration of the breakdown of the cytoskeleton promoting cell shrinkage and the destruction of the nuclear envelope and the fragmentation of the DNA. 
normally continuous but balanced molecular events, however during aging this balance is disrupted by the increased oxidative stress typical of aging [17]. The effects of age-related oxidative stress in skeletal muscle may determine not only this imbalance between protein synthesis and degradation, but also mitochondrial dysfunction and apoptosis by activating some major signaling pathways, leading to reduction in muscle mass and strength [4] [18]. Data from literature indicate that, in aging, increased apoptosis in skeletal muscle cell involves caspase-2 and c-Jun N-terminal kinase (JNK) mediated intrinsic pathway signaling activated by calcium and oxidative stress [19] [20], even if how JNK mediates ROS-induced apoptosis is not well determined [4]. Aging is also associated with increased DNA fragmentation and cleaved caspase-3 in rat skeletal muscle [3]. Finally, it has been shown that TNF- $\alpha$ is one of the primary signals inducing apoptosis in muscle cell, and that increased synthesis of TNF- $\alpha$ in aged skeletal muscle may act as a signal activating death receptors on the cell surface membrane [4] [5]. In addition, reactive oxygen species (ROS) appear to have a role as second messenger for TNF- $\alpha$ in skeletal muscle, activating the nuclear factor $\kappa \mathrm{b}$ (NF- $\kappa \mathrm{B}$ ) either directly or indirectly [4] [21] [22]. The latter is a major pleiotropic transcription factor modulating immune, inflammation, cell survival, and proliferation responses [4] [23]. Aging also affected TNF- $\alpha$ signaling to NF- $\kappa \mathrm{B}$, and, in addition, proteins such as IKK $\gamma$, $\mathrm{I} \kappa \mathrm{Ba}$, and $\mathrm{p} 65$, which are responsible for the TNF- $\alpha$ activation of NF- $\kappa \mathrm{B}$, result increased in the aged soleus muscle [4]. In recent studies, NF- $\kappa$ B concentrations resulted four-fold higher in elderly human muscles compared to those of young people, and this increased concentration was accompanied by anabolic signaling deficits observed in debilitated, aging muscle [4] [24]. However, the exact mechanism by which NF- $\kappa$ B acts in aging muscle is still to clarify [4].

\section{Discussion}

As reported above, age-related apoptosis pathways in skeletal muscle are numerous and not always clear, however a lot of study have been performed in the last decade, in order to establish if an appropriate life-style can improve the status of muscle tissue (and consequently of the musculoskeletal system) in aging [25]. At this regard, physical activity and nutrition are two topics highly considered. Physical exercise causes an increase in oxidative stress but at the same time it stimulates the adaptive response of the body against oxidative stress [26]. This cytoprotection is associated with several changes in gene expression, upregulation of cellular protective mechanisms and remodelling of the muscle structure, including also mitochondrial biogenesis [27]. There are several kinds of physical exercise, and each of them differently interferes with the various molecular mechanisms active in aging skeletal muscle. Endurance exercise enhances protein synthesis, mitochondrial biogenesis and the release of IL-6 resulting in inhibition of TNF- $\alpha$ production, it also may mediate anti-inflammatory and anti-atrophy effects, including the upregulation of PGC- $1 \alpha$ in muscle and downregulation of Toll-like receptors [4] [28]-[31]. Treadmill exercise training and resistance training can attenuate both fiber atrophy and pro-apoptotic signaling in aging skeletal muscle [4] [32] [33]. Moreover, resistance training can increase the activity of mitochondrial enzymes, and decreases skeletal muscle TNF- $\alpha$ in elderly humans [4] [33] [34]. A typical cytoprotective response in stressed skeletal muscle is the increased production of heat shock proteins (HSPs) in order to provide protection against subsequent periods of stress damage and to facilitate a rapid recovery and remodelling if damage occurs [27]. It has been seen that HSPs synthesis is induced in skeletal muscle by exercise [35] [36]. Although in aging skeletal muscle gene expression of antioxidant enzymes decreases and ROSs production increases, physically exercise seems to benefit adaptation of cell antioxidant defense system [25] [37] when supported with a good quality of nutrition or with supplementation of exogenous antioxidants in order to achieve an optimal level of defense [38]. For example, TNF- $\alpha$ stimulation of both inflammatory and apoptotic pathways was attenuated in aging rat skeletal muscle when caloric restriction was applied [5] [39]. A good quality of nutritional status can be achieved not only with caloric restriction but also thanks to some natural nutrients that have antioxidant properties, such as carotenoids and oleic acid. The latter is a typical compound of extra-virgin olive oil, a typical nutrientof the Mediterranean diet. In some recent studies, we showed its antioxidants properties not only in skeletal muscle but also in myocardium and cartilage [40]-[42].

\section{Conclusion}

In conclusion, we can assert that, probably, the best strategy in order to prevent or attenuate physiological molecular pathways that lead to the loss of skeletal muscle in aging, with all consequence on the physical wellbeing of the elderly, is a combination of physical exercise, caloric restriction and diet. In accordance with other 
authors [4], we think that this combination could improve the structure and function of muscle tissue through multipli mechanisms induced by activation of IGF-1/Akt/mTOR, PGC- $1 \alpha$, and/or other pathways including increased protein metabolism, redox balance, mitochondrial biogenesis and anti-inflammatory ability.

\section{Acknowledgements}

This study was supported by grants provided by FIR 2014-2016 (cod. 314509), University of Catania, Italy.

\section{Conflict of Interest}

The authors declare that do not have any conflict of interest.

\section{References}

[1] Fragala, M.S., Kenny, A.M. and Kuchel, G.A. (2015) Muscle Quality in Aging: A Multi-Dimensional Approach to Muscle Functioning with Applications for Treatment. Sports Medicine. http://dx.doi.org/10.1007/s40279-015-0305-Z

[2] Tudoraşcu, I., Sfredel, V., Riza, A.L., Dănciulescu Miulescu, R., Ianoşi, S.L. and Dănoiu, S. (2014) Motor Unit Changes in Normal Aging: A Brief Review. Romanian journal of morphology and embryology, 55, 1295-1301.

[3] Leeuwenburgh, C. (2003) Role of Apoptosis in Sarcopenia. The Journals of Gerontology. Series A, Biological Sciences and Medical Sciences, 58, 999-1001. http://dx.doi.org/10.1093/gerona/58.11.M999

[4] Meng, S.J. and Yu, L.J. (2010) Oxidative Stress, Molecular Inflammation and Sarcopenia. International Journal of Molecular Science, 11, 1509-1526. http://dx.doi.org/10.3390/ijms11041509

[5] Phillips, T. and Leeuwenburgh, C. (2005) Muscle Fiber Specific Apoptosis and TNF- $\alpha$ Signaling in Sarcopenia Are Attenuated by Life-Long Calorie Restriction. FASEB Journal, 19, 668-670.

[6] Nitahara, J.A., Cheng, W., Liu, Y., Li, B., Leri, A., Mogul, D., Gambert, S.R., Kajstura, J. and Anversa, P. (1998) Intracellular Calcium, DNase Activity and Myocyte Apoptosis in Aging Fischer 344 Rats. Journal of Molecular and Cellular Cardiology, 30, 519-535. http://dx.doi.org/10.1006/jmcc.1997.0616

[7] Cadenas, E. and Davies, K.J. (2000) Mitochondrial Free Radical Generation, Oxidative Stress, and Aging. Free Radical Biology \& Medicine, 9, 222-230. http://dx.doi.org/10.1016/S0891-5849(00)00317-8

[8] Musumeci, G., Loreto, C., Carnazza, M.L. and Martinez, G. (2011) Characterization of Apoptosis in Articular Cartilage Derived from the Knee Joints of Patients with Osteoarthritis. Knee Surgery Sports Traumatology Arthroscopy, 19, 307-313. http://dx.doi.org/10.1007/s00167-010-1215-0

[9] Majno, G. and Joris, I. (1995) Apoptosis, Oncosis, and Necrosis. An Overview of Cell Death. The American Journal of Pathology, 146, 3-15.

[10] Trump, B.F., Berezesky, I.K., Chang, S.H. and Phelps, P.C. (1997) The Pathways of Cell Death: Oncosis, Apoptosis, and Necrosis. Toxicologic Pathology, 25, 82-88. http://dx.doi.org/10.1177/019262339702500116

[11] Ganguly, R. and Pierce, G.N. (2015) The Toxicity of Dietary Trans Fats. Food and Chemical Toxicology, 78, $170-176$. http://dx.doi.org/10.1016/j.fct.2015.02.004

[12] Ghobrial, I.M., Witzig, T.E. and Adjei, A.A. (2005) Targeting Apoptosis Pathways in Cancer Therapy. CA: A Cancer Journal for Clinicians, 55, 178-194. http://dx.doi.org/10.3322/canjclin.55.3.178

[13] Fulda, S. and Debatin, K.M. (2004) Apoptosis Signaling in Tumor Therapy. Annals of the New York Academy of Sciences, 1028, 150-156. http://dx.doi.org/10.1196/annals.1322.016

[14] Chabi, B., Ljubicic, V., Menzies, K.J., Huang, J.H., Sallem, A. and Hood, D.A. (2008) Mitochondrial Function and Apoptotic Susceptibility in Aging Skeletal Muscle. Aging Cell, 7, 2-12. http://dx.doi.org/10.1111/j.1474-9726.2007.00347.x

[15] Akl, H., Vervloessem, T., Kiviluoto, S., Bittremieux, M., Parys, J.B., De Smedt, H. and Bultynck, G. (2014) A Dual role for the Anti-Apoptotic Bcl-2 Protein in Cancer: Mitochondria versus Endoplasmic Reticulum. Biochimica et Biophysica Acta, 1843, 2240-2252. http://dx.doi.org/10.1016/j.bbamcr.2014.04.017

[16] Marzetti, E., Wohlgemutz, S.E., Lees, H.A., Chung, H., Giovannini, S. and Leeuwenburgh, C. (2008) Age-Related Activation of Mitochondrial Caspase-Independent Apoptotic Signaling in Rat Gastrocnemius Muscle. Mechanisms of Ageing and Development, 129, 542-549. http://dx.doi.org/10.1016/j.mad.2008.05.005

[17] Koopman, R. and van Loon, L.J. (2009) Aging, Exercise and Muscle Protein Metabolism. Journal of Applied Physiology, 106, 2040-2048.

[18] Carter, C.S., Hofer, T., Seo, A.T. and Leeuwenburgh, C. (2007) Molecular Mechanisms of Life- and Health-Span Extension: Role of Calorie Restriction and Exercise Intervention. Applied Physiology, Nutrition, and Metabolism, 32, 
954-966. http://dx.doi.org/10.1139/H07-085

[19] Shen, H.M. and Liu, Z.G. (2006) JNK Signaling Pathway Is a Key Modulator in Cell Death Mediated by Reactive Oxygen and Nitrogen Species. Free Radical Biology \& Medicine, 40, 928-939.

http://dx.doi.org/10.1016/j.freeradbiomed.2005.10.056

[20] Braga, M., Sinha-Hikim, A.P., Datta, S., Ferrini, M.G., Brown, D., Kovacheva, E.L., Gonzalez Cadavid, N.F. and Sinha-Hikim, I. (2008) Involvement of Oxidative Stress and Caspase 2-Mediated Intrinsic Pathway Signaling in AgeRelated Increase in Muscle Cell Apoptosis in Mice. Apoptosis, 13, 822-832. http://dx.doi.org/10.1007/s10495-008-0216-7

[21] Chung, H.Y., Cesari, M., Anton, S., Marzetti, E., Giovannini, S., Seo, A.Y., Carter, C., Yu, B.P. and Leeuwenburgh, C. (2009) Molecular Inflammation: Underpinnings of Aging and Age-Related Diseases. Ageing Research Reviews, 8, 1830. http://dx.doi.org/10.1016/j.arr.2008.07.002

[22] Reid, M.B. and Li, Y.P. (2001) Tumor Necrosis Factor- $\alpha$ and Muscle Wasting: A Cellular Perspective. Respiratory Research, 2, 269-272. http://dx.doi.org/10.1186/rr67

[23] Piette, J., Piret, B., Bonizzi, G., Schoonbroodt, S., Merville, M.P., Legrand-Poels, S. and Bours, V. (1997) Multiple Redox Regulation in NF- $\kappa$ B Transcription Factor Activation. Biological Chemistry, 378, 1237-1245.

[24] Cuthbertson, D., Smith, K., Babraj, J., Leese, G., Waddell, T., Atherton, P., Wackerhage, H., Taylor, P.M. and Rennie, M.J. (2005) Anabolic Signaling Deficits Underlie Amino Acid Resistance of Wasting, Aging Muscle. FASEB Journal, 19, $422-424$.

[25] Musumeci, G., Szychlinska, M.A. and Mobasheri, A. (2015) Age-Related Degeneration of Articular Cartilage in the Pathogenesis of Osteoarthritis: Molecular Markers of Senescent Chondrocytes. Histology and Histopathology, 30, 1-12. http://dx.doi.org/10.7243/2055-091X-2-1

[26] Castrogiovanni, P. and Imbesi, R. (2012) Oxidative Stress and Skeletal Muscle in Exercise. Italian Journal of Anatomy and Embryology, 17, 107-117.

[27] McArdle, A., Vasilaki, A. and Jackson, M. (2002) Exercise and Skeletal Muscle Ageing: Cellular and Molecular Mechanisms. Ageing Research Reviews, 1, 79-93. http://dx.doi.org/10.1016/S0047-6374(01)00368-2

[28] Menshikova, E.V., Ritov, V.B., Fairfull, L., Ferrell, R.E., Kelley, D.E. and Goodpaster, B.H. (2006) Effects of Exercise on Mitochondrial Content and Function in Aging Human Skeletal Muscle. The Journals of Gerontology. Series A, Biological Sciences and Medical Sciences, 61, 534-540. http://dx.doi.org/10.1093/gerona/61.6.534

[29] Russell, A.P., Feilchenfeldt, J., Schreiber, S., Praz, M., Crettenand, A., Gobelet, C., Meier, C.A., Bell, D.R., Kralli, A., Giacobino, J.P. and Dériaz, O. (2003) Endurance Training in Humans Leads to Fiber Type-Specific Increases in Levels of Peroxisome Proliferator-Activated Receptor-Gamma Coactivator-1 and Peroxisome Proliferator-Activated Receptor-Alpha in Skeletal Muscle. Diabetes, 52, 2874-2881. http://dx.doi.org/10.2337/diabetes.52.12.2874

[30] Gleeson, M., McFarlin, B. and Flynn, M. (2006) Exercise and Toll-Like Receptors. Exercise Immunology Review, 12, 34-53.

[31] Petersen, A.M. and Pedersen, B.K. (2005) The Anti-Inflammatory Effect of Exercise. Journal of Applied Physiology, 98, 1154-1162.

[32] Song, W., Kwak, H.B. and Lawler, J.M. (2006) Exercise Training Attenuates Age-Induced Changes in Apoptotic Signaling in Rat Skeletal Muscle. Antioxidants \& Redox Signaling, 8, 517-528. http://dx.doi.org/10.1089/ars.2006.8.517

[33] Greiwe, J.S., Cheng, B., Rubin, D.C., Yarasheski, K.E. and Semenkovich, C.F. (2001) Resistance Exercise Decreases Skeletal Muscle Tumor Necrosis Factor Alpha in Frail Elderly Humans. FASEB Journal, 15, 475-482. http://dx.doi.org/10.1096/fj.00-0274com

[34] Melov, S., Tarnopolsky, M.A., Beckman, K., Felkey, K. and Hubbard, A. (2007) Resistance Exercise Reverses Aging in Human Skeletal Muscle. PLoS ONE, 2, e465. http://dx.doi.org/10.1371/journal.pone.0000465

[35] Jackson, M.J. (2009) Strategies for Reducing Oxidative Damage in Ageing Skeletal Muscle. Advanced Drug Delivery Reviews, 61, 1363-1368. http://dx.doi.org/10.1016/j.addr.2009.07.018

[36] Khassaf, M., Child, R.B., McArdle, A., Brodie, D.A., Esanu, C. and Jackson, M.J. (1985) Time Course of Responses of Human Skeletal Muscle to Oxidative Stress Induced by Non-Damaging Exercise. Journal of Applied Physiology, 90, 1031-1035.

[37] Imbesi, R., D’agata, V., Musumeci, G. and Castogiovanni, P. (2014) Skeletal Muscle: From Development to Function. La Clinica Terapeutica, 165, 47-56.

[38] Gomez-Cabrera, M.C., Viña, J. and Ji, L.L. (2009) Interplay of Oxidants and Antioxidants during Exercise: Implications for Muscle Health. The Physician and Sports-Medicine, 37, 116-123. http://dx.doi.org/10.3810/psm.2009.12.1749

[39] Musumeci, G., Castrogiovanni, P., Coleman, R., Szychlinska, M.A., Salvatorelli, L., Parenti, R., Magro, G. and Imbesi, R. (2015) Somitogenesis: From Somite to Skeletal Muscle. Acta Histochemica, Published Online. 
http://dx.doi.org/10.1016/j.acthis.2015.02.011

[40] Musumeci, G., Trovato, F.M., Imbesi, R. and Castrogiovanni, P. (2014) Effects of Dietary Extra-Virgin Olive Oil on Oxidative Stress Resulting from Exhaustive Exercise in Rat Skeletal Muscle: A Morphological Study. Acta Histochemica, 116, 61-69. http://dx.doi.org/10.1016/j.acthis.2013.05.006

[41] Castrogiovanni, P. and Imbesi, R. (2006) Muscle in Exercise. Role of Different Fatty Acids in Diets. Italian Journal of Anatomy and Embryology, 111, 199-214.

[42] Musumeci, G., Trovato, F.M., Pichler, K., Weinberg, A.M., Loreto, C. and Castrogiovanni, P. (2013) Extra-Virgin Olive Oil Diet and Mild Physical Activity Prevent Cartilage Degeneration in an Osteoarthritis Model: An in Vivo and in Vitro Study on Lubricin Expression. The Journal of Nutritional Biochemistry, 24, 2064-2975.

http://dx.doi.org/10.1016/j.jnutbio.2013.07.007 